\title{
Molecular Characterization of a New ALK Translocation Involving Moesin (MSN-ALK) in Anaplastic Large Cell Lymphoma
}

\author{
Frederic Tort, Magda Pinyol, Karen Pulford, Giovanna Roncador, Lluis Hernandez, \\ Iracema Nayach, Hanneke C. Kluin-Nelemans, Philip Kluin, Christian Touriol, \\ Georges Delsol, David Mason, and Elias Campo
}

Laboratory of Pathology (FT, MP, LH, IN, EC), Hospital Clinic, Institut d'Investigacions Biomediques August Pi i Sunyer, University of Barcelona, Barcelona, Spain; LRF Immunodiagnostics Unit (KP, GR, DM), Nuffield Department of Clinical Biochemistry and Cellular Science, John Radcliffe Hospital, Oxford, United Kingdom; Laboratory Department of Pathology and UPCM-ERS 1590 CNRS (CT, GD), CHU Purpan, Toulouse, France; and Departments of Hematology (HCKN) and Pathology (PK), Leiden University Medical Center, Leiden, The Netherlands

\begin{abstract}
SUMMARY: The majority of anaplastic large cell lymphomas (ALCL) are associated with chromosomal abnormalities affecting the anaplastic lymphoma kinase (ALK) gene which result in the expression of hybrid ALK fusion proteins in the tumor cells. In most of these tumors, the hybrid gene comprises the $5^{\prime}$ region of nucleophosmin (NPM) fused in frame to the $3^{\prime}$ portion of $A L K$, resulting in the expression of the chimeric oncogenic tyrosine kinase NPM-ALK. However, other variant rearrangements have been described in which ALK fuses to a partner other than NPM. Here we have identified the moesin (MSN) gene at Xq11-12 as a new partner of ALK in a case of ALCL which exhibited a distinctive membrane-restricted pattern of ALK labeling. The hybrid MSN-ALK protein had a molecular weight of $125 \mathrm{kd}$ and contained an active tyrosine kinase domain. The unique membrane staining pattern of ALK is presumed to reflect association of moesin with cell membrane proteins. In contrast to other translocations involving the $A L K$ gene, the $A L K$ breakpoint in this case occurred within the exonic sequence coding for the juxtamembrane portion of $A L K$. Identification of the genomic breakpoint confirmed the in-frame fusion of the whole $M S N$ intron 10 to a 17 bp shorter juxtamembrane exon of $A L K$. The breakpoint in der(2) chromosome showed a deletion, including 30 bp of $A L K$ and $36 \mathrm{bp}$ of MSN genes. These findings indicate that MSN may act as an alternative fusion partner for activation of ALK in ALCL and provide further evidence that oncogenic activation of ALK may occur at different intracellular locations. (Lab Invest 2001, 81:419-426).
\end{abstract}

A naplastic large cell lymphoma (ALCL) is associated with chromosomal translocations affecting the anaplastic lymphoma kinase (ALK) gene at 2p23. These translocations lead to the synthesis of novel chimeric ALK proteins with transforming properties. In most of these tumors, the $(2 ; 5)(\mathrm{p} 23 ; \mathrm{q} 35)$ translocation causes fusion of the gene to the region of the nucleophosmin (NPM) gene (Bitter et al, 1990; Mason et al, 1990; Morris et al, 1994). This rearrangement generates a novel fusion protein NPM-ALK of $80 \mathrm{kd}$ molecular weight, which contains the $\mathrm{N}$-terminal region of NPM fused to the C-terminal region of ALK (Bischof et al, 1997; Fujimoto et al, 1996; Mason et al, 1998; Morris et al, 1994). The ALK gene encodes a tyrosine

\section{Received December 21, 2000.}

This work was supported by the Comision Interministerial de Ciencia $y$ Tecnologia (SAF 99/20): Asociacion Española Contra el Cancer; CIRIT, Generalitat de Catalunya (98SGR21), and Ligue Nationale Contre le Cancer, PHRC 1998.

Address reprint requests to: Dr. Elias Campo, Laboratory of Pathology, Hospital Clinic, Villarroel 170, 08036-Barcelona, Spain. E-mail: campo@medicina.ub.es kinase receptor that seems to play a role in the development of the nervous system. Recent studies showed that $A L K$ mRNA and/or protein is only detected in neural cells, neuroblastomas, and neural cell lines, whereas it is not found in any normal or neoplastic hematopoietic tissues (Iwahara et al, 1997; Lamant et al, 2000; Morris et al, 1997; Pulford et al, 1997). In contrast, NPM protein is ubiquitously expressed in normal cells, being involved in shuttling ribonucleoproteins from the cytoplasm to the nucleus (Chan et al, 1989, 1997). As found for other proteins implicated in oncogenic tyrosine kinases, a dimerization motif within the NPM protein moiety mimics ligand binding and results in the constitutive activation of the tyrosine kinase (Bischof et al, 1997; Chan et al, 1989, 1997).

Several cytogenetic and molecular studies have now demonstrated that chromosome aberration other than $\mathrm{t}(2 ; 5)(\mathrm{p} 23 ; \mathrm{q} 35)$ may give rise to novel ALK fusion genes in ALCL (Falini et al, 1998; Lamant et al, 1996; Mitev et al, 1998; Park et al, 1997; Pittaluga et al, 1997; Pulford et al, 1997; Rosenwald et al, 1999; Sainati et al, 1990; Wlodarska et al, 1998). Four different genes, 
nonmuscle tropomyosin (TPM3), TRK-fused gene (TFG), 5'aminoimidazole-4-carboxamide ribonucleotide formyltranferase/IMP cyclohydrolase (ATIC), and clathrin chain polypeptide-like gene (CLTCL), have been cloned as alternative partners to NPM (Colleoni et al, 2000; Hernandez et al, 1999; Lamant et al, 1999; Ma et al, 2000; Touriol et al, 2000; Trinei et al, 2000). These variant translocations encode ALK fusion tyrosine kinases with molecular weights ranging from 85 to $245 \mathrm{kd}$. Contrary to the nuclear and cytoplasmic distribution of the NPM-ALK protein, variant fusion proteins show a cytoplasmic restricted pattern (Colleoni et al, 2000; Hernandez et al, 1999; Lamant et al, 1999; Ma et al, 2000; Touriol et al, 2000; Trinei et al, 2000).

In the present report, we study a case ALCL with a unique ALK staining pattern restricted to the cell membrane and show that the gene fused to ALK is moesin (MSN). Biochemical analysis showed that the new fusion protein had a molecular weight of about $125 \mathrm{kd}$ and tyrosine kinase activity in vitro. The break- point within the $A L K$ gene was different from that observed in NPM-ALK gene and all of its reported variants.

\section{Results}

\section{Immunomorphologic Characteristics}

The lymph node biopsy showed the typical ALCL features of "common" morphology expressing CD4, CD30, and epithelial membrane antigen (EMA). The tumor cells were negative for CD2, CD3, CD43, CD8, CD15, CD19, and CD22. Immunostaining with ALKc and ALK-1 antibodies was positive in all tumor cells. However, contrary to previously described patterns, this case revealed a peculiar membrane distribution of ALK protein with strong accentuation of the cellular contour without cytoplasmic or nuclear staining. A similar pattern of labeling for phosphotyrosine was also observed with all of the ALK-positive cells expressing phosphotyrosine (Fig. 1). RT-PCR studies for

\section{A}

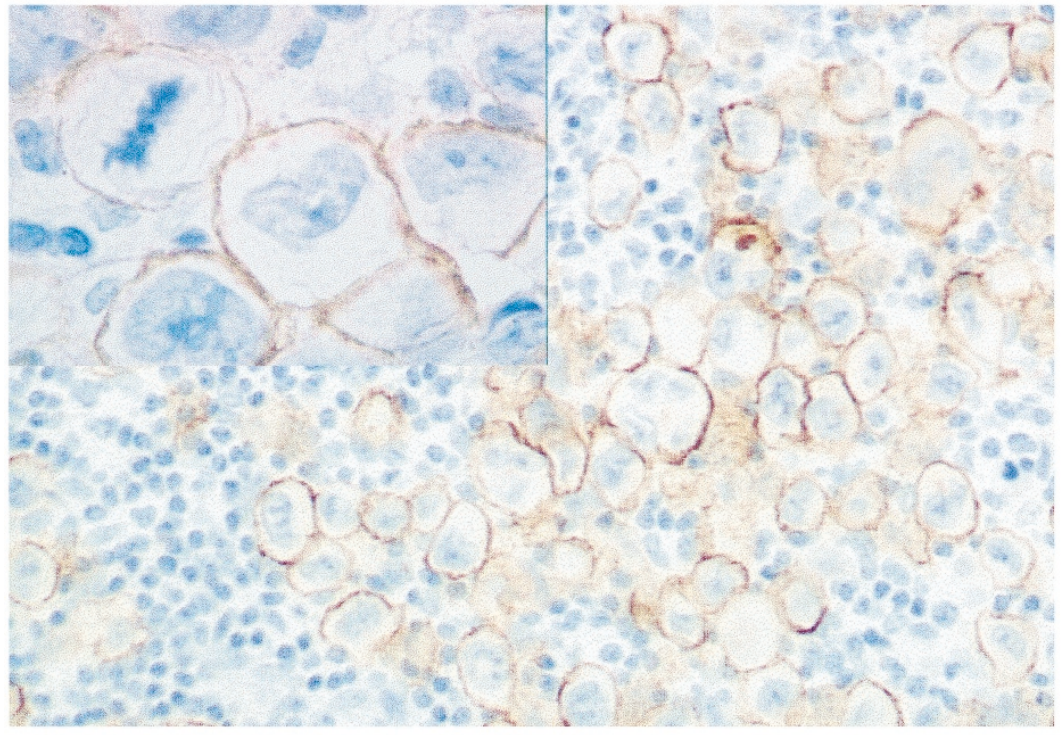

B
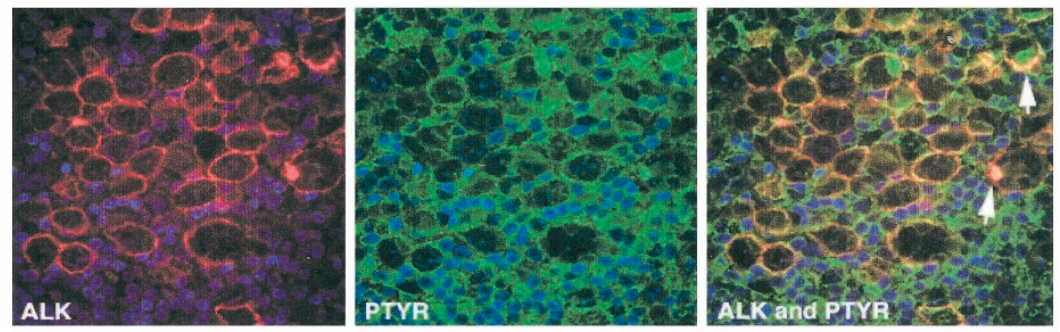

Figure 1.

Immunohistochemical analysis. A, The immunohistochemical staining of ALK in the present case shows a cell membrane-restricted pattern. B, Double immunofluorescent labeling for ALK (red) and phosphotyrosine (green) showing coexpression in the same cells and the same sites. Examples are indicated by arrows. 
the previously described NPM-ALK, TPM3-ALK, TFG$A L K, A T I C-A L K$, and CLTCL-ALK chimeric products were negative.

\section{Molecular Characterization of Moesin as a New Partner of ALK}

To identify the gene involved in this new ALK translocation, we used a $5^{\prime}$ rapid amplification of the cDNA end (RACE) technique with ALK primers close to the known breakpoint in other translocations. A $321 \mathrm{bp}$ PCR product was amplified with this strategy, and its specificity was confirmed by Southern blot using an internal $A L K$ oligonucleotide probe. The sequence of this product revealed a known ALK sequence fused in frame to a portion of the moesin (MSN) gene that was mapped to chromosome Xq11-12. The ALK breakpoint in this chimeric $M S N-A L K$ cDNA was at nucleotide 4100 , which is $17 \mathrm{bp}$ downstream of the breakpoint identified in all other $A L K$ translocations previously described (Fig. 2A). The MSN breakpoint was located at nucleotide 1444, close to its $3^{\prime}$ end (GenBank accession number, M69066). Using primers from the $5^{\prime}$ untranslated region of $M S N$ and $A L K$, we could amplify the whole MSN fragment present in this translocation. Sequencing analysis of this product confirmed that it was identical to the MSN sequence previously described and included the complete $\mathrm{N}$-terminal domain responsible for the interactions of MSN protein with cell membrane proteins.

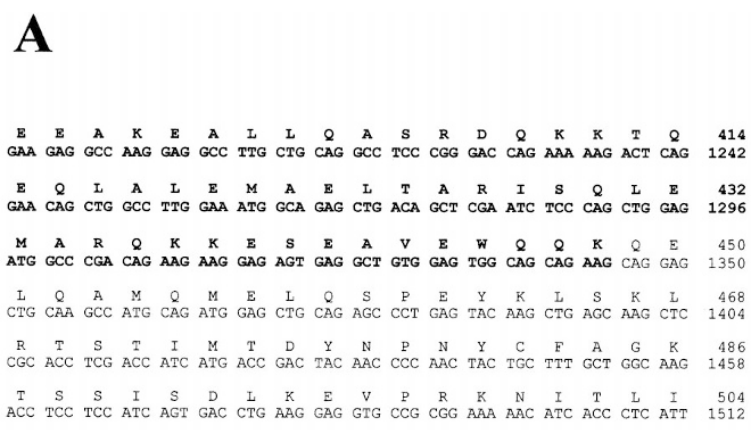

\section{B}

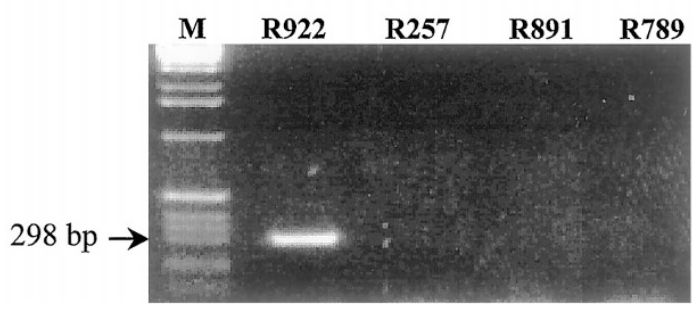

Figure 2.

RT-PCR detection of MSN-ALK transcript and CDNA breakpoint sequence. A, Nucleotide and amino acid sequence of the MSN-ALK CDNA junction. Nucleotides and amino acids are numbered from the beginning of the predicted MSN-ALK open reading frame. MSN sequence is in bold letters (Genbank accession number: AF295356). B, Only sample R922 showed the predicted MSN-ALK 298 bp band by RT-PCR analysis. RNA from ALCLs carrying the NPM-ALK (R257), TPM3-ALK (R891), and TFG-ALK (R789) translocations was used as a negative control and showed no evidence of the MSN-ALK transcript.

\section{Identification of the MSN-ALK and Reciprocal ALK-MSN Genomic Breakpoints}

To determine the genomic breakpoint of this translocation, we amplified the region between the $3^{\prime}$ end of $M S N$ exon 10 and the $5^{\prime}$ end of the juxtamembrane portion of $A L K$ included in the chimeric MSN-ALK. Sequencing demonstrated the MSN genomic breakpoint in this case to be located exactly at the end of intron 10, including the consensus acceptor-donor splicing sequences. This MSN intronic sequence was directly fused to the juxtamembrane exon of $A L K, 17$ bp downstream of the beginning of the exon (Fig. 3).

The genomic breakpoint of the derivative translocation on chromosome 2 was amplified using primers of the MSN exon 11 and the intronic region of $A L K$ between the transmembrane and juxtamembrane exons. The amplified product was a 155 bp fragment, 66 bp shorter than the expected size. Sequencing analysis revealed that the derivative breakpoint of $A L K$ was located $13 \mathrm{bp}$ upstream of the $5^{\prime}$ end of the juxtamembrane exon. This $A L K$ intronic sequence was directly fused to the exon 11 of the MSN gene, $36 \mathrm{bp}$ downstream of the beginning of the exon. Therefore, the breakpoint in the derivative 2 translocation had a $66 \mathrm{bp}$ deletion, including $13 \mathrm{bp}$ of intronic and $17 \mathrm{bp}$ of exonic $A L K$ sequence together with the first $36 \mathrm{bp}$ of MSN exon 11 (Fig. 3).

\section{Expression of the MSN-ALK Transcript}

To confirm the existence of the $M S N-A L K$ fusion transcript in the original lymph node biopsy, an RTPCR technique was performed using MSN- and ALKspecific primers. This amplification yielded the expected 298 bp band, whose specificity was confirmed by hybridization with an $A L K$-specific oligonucleotide probe and subsequent sequencing analysis. No band was detected in any of the other ALCL that were analyzed (Fig. 2B). Expression of the reciprocal ALKMSN fusion cDNA was not detectable by RT-PCR.

\section{MSN-ALK Fusion Protein}

The predicted chimeric MSN-ALK protein was composed of 1005 amino acids with an estimated molecular weight of $115 \mathrm{kd}$. The $\mathrm{N}$-terminal region of the fusion protein corresponded to the first 448 amino acids of MSN, whereas the other 557 amino acids were encoded by ALK and contained the tyrosine kinase domain. Western blot analysis of the ALK

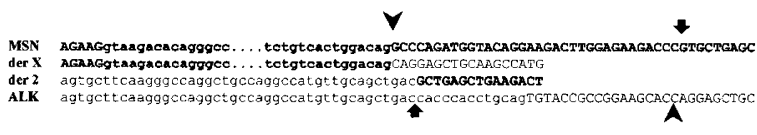

Figure 3.

Sequence analysis of the genomic junction for both derivatives of the MSN-ALK translocation. Exons and introns are represented by upper- and lower-case letters, respectively. MSN gene is indicated by bold characters. Arrowheads show the breakpoints in $\operatorname{der}(\mathrm{X})$ whereas arrows indicate the breakpoints in $\operatorname{der}(2)$. Sequences between the arrows were deleted in the translocation (Genbank accession numbers: AF295078 and AF295079, respectively). 
protein present in the ALCL tissue confirmed the presence of a protein with a molecular weight of 125 $\mathrm{kd}$, which was consistent with the predicted size of the MSN-ALK fusion protein (Fig. 4A).

The in vitro kinase assay of proteins immunoprecipitated with anti-ALK and anti-phosphotyrosine from cryostat sections of the ALCL case demonstrated the presence of a $125 \mathrm{kd}$ phosphorylated protein corre-

A

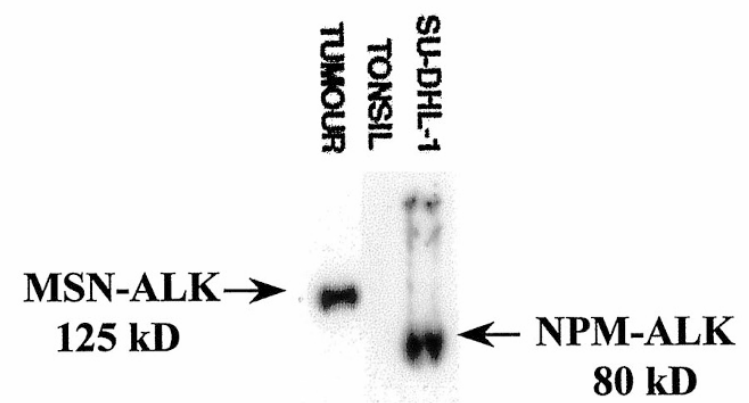

B
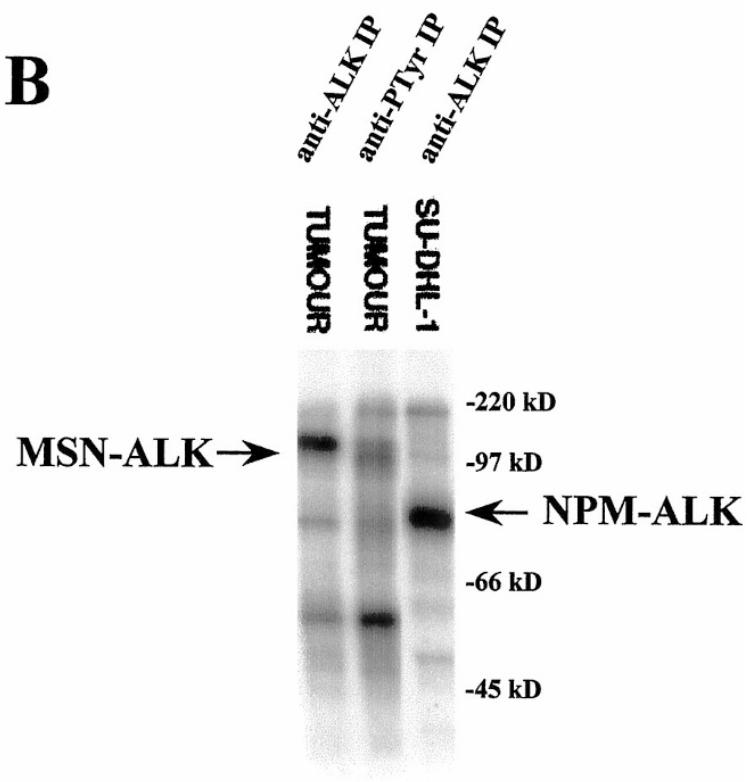

Figure 4.

Biochemical assays of proteins extracted from cryostat tissue sections and cytocentrifuge preparations. A, Western blotting of proteins extracted from sections of the anaplastic large cell lymphoma (ALCL) case using anti-ALK (ALKc) demonstrated the presence of a $125 \mathrm{kd}$ protein (MSN-ALK) in the tumor cells. This was in contrast to the $80 \mathrm{kd}$ NPM-ALK protein detected in the $\mathrm{t}(2 ; 5)$-positive SU-DHL-1 cell line. No ALK proteins were detected in normal tonsil lysates used as a negative control. B, An in vitro kinase assay of proteins immunoprecipitated with anti-ALK from the ALCL tumor demonstrated the presence of a $125 \mathrm{kd}$ phosphorylated protein. A weaker band of comparable size was also observed in proteins immunoprecipitated by antiphosphotyrosine. In the ALK immunoprecipitates from the SU-DHL-1 cell line, the only band seen represents the $80 \mathrm{kd}$ NPM-ALK. sponding in size to MSN-ALK (Fig. 4B). These results indicate that the tyrosine kinase domain in the MSNALK protein is active, resulting in autophosphorylation in vitro.

\section{Discussion}

In the present study, we have characterized a new chimeric $A L K$ translocation in a case of ALCL in which ALK protein showed a unique cell membraneassociated distribution. Using a 5' RACE strategy, we identified an in-frame fusion of the $5^{\prime}$ region of moesin (MSN) gene to the $3^{\prime}$ portion of $A L K$ containing the catalytic domain. This gene has been mapped to chromosome Xq11-12, and demonstrates that the chimeric $M S N-A L K$ gene is the result of a $(X ; 2)(q 11-$ 12;p23) translocation, a chromosomal abnormality not previously described in ALK-positive ALCL.

Moesin is a $75 \mathrm{kd}$ protein that belongs to the highly homologous ERM (ezrin/radixin/moesin) protein family. These proteins have been shown to localize beneath the cell membrane and are considered to act as cross-linkers between the plasma membrane and the cortical actin cytoskeleton, playing a major role in cell adhesion and motility (Bretscher, 1999; Tsukita and Yonemura, 1997a, 1997b, 1999). As is the case for other fusion partners of ALK, moesin is widely expressed in normal cells, including $B$ and $T$ lymphocytes (Berryman et al, 1993; Masumoto et al, 1998). Structurally, moesin is characterized by a globular $\mathrm{N}$-terminal membrane-binding domain, followed by a large $\alpha$-helix domain, and a $\mathrm{C}$-terminal region with a consensus sequence for actin binding. In normal steady-state situations, the amino-terminal and C-terminal domains of a single moesin molecule may bind to each other in a head-to-tail manner, resulting in the inactivation of the protein by preventing its interaction with both cell membrane proteins and the actin cytoskeleton (Bretscher, 1999; Tsukita and Yonemura, 1997a, 1997b, 1999). Phosphorylation of the $\mathrm{N}$ - and C-terminal domains seems to act as an activation signal inhibiting this intramolecular interaction, thereby permitting the simultaneous binding of the $\mathrm{N}$-terminus of MSN to membrane proteins (eg, CD43, CD44, CD50 and proteins containing the PDZ dimerization) and binding of the C-terminus to actin (Bretscher, 1999; Fouassier et al, 2000; Reczek et al, 1997; Tsukita and Yonemura, 1997a, 1997b, 1999).

The predicted chimeric MSN-ALK protein in this tumor comprises the first 448 residues of MSN, including the complete $\mathrm{N}$-terminal globular domain and almost all the $\alpha$-helix region. The rest of the moesin protein is replaced by the C-terminal portion of ALK containing the kinase catalytic domain. The unique labeling pattern of ALK found in the tumor cells of this case presumably reflects binding to the cell surface membrane of MSN-ALK through the intact MSN $\mathrm{N}$-terminus. Experimental deletion of the C-terminal end of the moesin-homolog erzin activates this protein, allowing its direct interaction with cell membrane proteins (Reczek and Bretscher, 1998). Thus, in the hybrid MSN-ALK protein, substitution of the moesin 
C-end sequence by ALK may represent a comparable mechanism for the activation of the $\mathrm{N}$-terminal domain. It is also possible that the binding properties of moesin to cell membrane proteins may lead to dimerization of the MSN-ALK proteins, permitting the constitutive phosphorylation of the chimeric MSN-ALK protein through its intact kinase domain. Additional evidence was obtained from the comparable patterns of immuno-labeling of tumor cells obtained using both the anti-ALK and anti-phosphotyrosine antibodies because a previous study has demonstrated that the immunohistological detection of increased levels of phosphotyrosine provides evidence for the presence of activated tyrosine kinases (Pulford et al, 1999a).

In contrast to other rearrangements involving the $A L K$ gene in which the $A L K$ breakpoint consistently occurs in the same intron, between the transmembrane and juxtamembrane exonic sequences (Downing et al, 1995; Hernandez et al, 1999; Lamant et al, 1999; Ma et al, 2000; Sarris et al, 1998; Touriol et al, 2000; Trinei et al, 2000), the ALK breakpoint in the $M S N-A L K$ translocation is localized in an exonic sequence, $17 \mathrm{bp}$ downstream of the $5^{\prime}$ end of the first $A L K$ exon present in other translocations. Characterization of the genomic derivative chromosome $\mathrm{X}$ breakpoint confirmed that the whole MSN intron 10 was fused in frame to this $A L K$ exonic sequence, maintaining the consensus splicing signal. Amplification and sequencing of the reciprocal $A L K-M S N$ breakpoint on derivative chromosome 2 showed a 66 bp deletion, including both $A L K$ and $M S N$ sequences, as has been described for reciprocal translocations (Downing et al, 1995; Zucman-Rossi et al, 1998). Although the genomic breakpoint of the NPM-ALK translocation has been characterized in several ALCL, the sequence of derivative ALK chromosome has been examined in only a limited number of cases (Beylot-Barry et al, 1998). Similarly to these studies, we have not been able to identify a possible mechanism for the generation of this translocation.

All of the different protein partners in the ALK fusion proteins identified thus far are functionally important because they induce the activation of the ALK kinase domain (Bischof et al, 1997; Colleoni et al, 2000; Fujimoto et al, 1996; Hernandez et al, 1999; Lamant et al, 1999; Ma et al, 2000; Mason et al, 1998; Morris et al, 1994; Touriol et al, 2000; Trinei et al, 2000). Furthermore, the partner protein determines the subcellular localization of the chimeric ALK protein. Thus, the classic NPM-ALK fusion protein is localized in both the nucleus and the cytoplasm, whereas TFG-ALK and ATIC-ALK show a diffuse staining restricted to the cytoplasm (Colleoni et al, 2000; Hernandez et al, 1999; Trinei et al, 2000), TPM3-ALK shows a diffuse cytoplasmic distribution with peripheral intensification (Lamant et al, 1999), and CLTC-ALK shows a finely granular intracytoplasmic pattern (Touriol et al, 2000). The MSN-ALK translocation described in this study is associated with a distinctive ALK staining restricted to the cell membrane. All of these observations indicate that the oncogenic activation of ALK may occur in different cytoplasmic compartments. In addition, the different ALK immunostaining patterns may be a relatively good indicator of the underlying cytogenetic alteration present in the tumor.

\section{Materials and Methods}

\section{Patient}

An 18-year-old man presented with cervical lymphadenopathy and a paragastric mass. Biopsy of a cervical lymph node was diagnostic of CD30-positive ALCL of null/T-cell phenotype expressing ALK protein. Staging of the patient, including CD30 immunohistochemical analysis of the bone marrow biopsy, revealed stage IIlb disease. He was treated according to one of both arms of the EORTC 20901 trial, consisting of 6 cycles of $\mathrm{CHVmP/BV}$ (doxorubicin, teniposide, cyclophosphamide, prednisone, vincristine, and bleomycin) followed by autologous bone marrow transplant. The patient achieved complete remission but died in a car accident 14 months after diagnosis.

\section{Preparation of Frozen Tissue Sections and Cells}

Fresh and routinely processed paraffin-embedded samples from the ALCL were obtained from the Department of Pathology (Leiden University Medical Center, Leiden, The Netherlands). Fresh tonsil was obtained from the Ear, Nose and Throat Department (Radcliffe Infirmary, Oxford, United Kingdom). Cryostat sections (6- $\mu \mathrm{m}$ thickness) were cut from both the ALCL case and from fresh tonsil. The ALCL-derived $t(2 ; 5)$-positive SU-DHL-1 cell line was maintained in culture and cytocentrifuge preparations made as previously described (Pulford et al, 1997, 1999b). All tissue sections and cytocentrifuge preparations were fixed in acetone for 10 minutes and stored at $-70^{\circ} \mathrm{C}$.

\section{Immunolabeling}

Immunohistological staining was performed using the following panel of antibodies: polyclonal anti-CD3, monoclonal anti-CD2 (T9-10), anti-CD8 (C8/144), anti-CD15 (By87), anti-CD19 (Leu12), anti-CD30 (BerH2), anti-CD43 (DFT1), and EMA (E29). Sections were also stained with two anti-ALK monoclonal antibodies (ALK1 and ALKC) and with monoclonal antiphosphotyrosine (PY72.10.5) donated by Dr. N. Hogg (Imperial Cancer Research Fund, London, United Kingdom) (Falini et al, 1998; Pulford et al, 1997).

Double immunofluorescent labeling was performed using anti-ALK (ALK1-lgG3 isotype) and antiphosphotyrosine (IgG1 isotype), followed by goat antimouse subclass-specific antibodies conjugated to either fluorescein isothiocyanate (FITC) or Texas Red $^{\mathrm{TM}}$ (Eurogenetics, Middlesex, United Kingdom) as previously described. Slides were viewed on a conventional fluorescent microscope equipped with a cooled CCD camera (Mason et al, 2000; Pulford et al, 1999a). 


\section{Biochemical Studies}

Western blotting of proteins extracted from cryostat sections and cytocentrifuge preparations of the cultured SU-DHL-1 cell lines was performed as previously described (Pulford et al, 1999b). Briefly, the samples were incubated with $50 \mu$ l of sample buffer for 5 minutes at room temperature. The buffer was removed, heated to $95^{\circ} \mathrm{C}$ for 4 minutes, and subjected to SDS-PAGE. After transfer to Immobilon (Serva, Heidelberg, Germany), the separated proteins were detected using a monoclonal anti-ALK (ALKC) reagent.

An in vitro kinase assay using tissue sections and cytocentrifuge preparations was performed as previously described (Pulford et al, 1999b). Briefly, cryostat tissue sections of ALCL and tissue sections and cytocentrifuge preparations were lysed in buffer containing 1\% Brij 97, $140 \mathrm{~mm} \mathrm{NaCl}, 25 \mathrm{~mm}$ Tris $\mathrm{pH}$ 7.6, 10 $\mathrm{mm} \mathrm{NaF}, 1 \mathrm{~mm} \mathrm{Na}(\mathrm{VO})_{4}, 1 \mathrm{mg} / \mathrm{ml}$ bovine serum albumin, and metabolic inhibitors (1 mM leupeptin, 1 $\mathrm{mm}$ pepstatin, $1 \mathrm{~mm}$ Pefabloc and $20 \mathrm{~mm}$ tosyl-Lphenylalanine chloromethyl ketone) (BoehringerMannheim, Lewes, United Kingdom). The samples were precleared for 2 hours with $200 \mu \mathrm{l}$ of $20 \%$ (vol/vol) of Protein G (Sepharose; Pharmacia, Uppsala, Sweden). ALK proteins from the precleared lysates were then immunoprecipitated using $50 \mu \mathrm{l}$ of Protein $G$ Sepharose preloaded with either monoclonal antiALK antibody (ALK1) or antiphosphotyrosine (4G10; Upstate Biotechnology Inc., Lake Placid, New York). After washing, the samples were added to $5 \mu \mathrm{Ci}{ }^{32} \mathrm{P}$ ATP in $20 \mu \mathrm{l}$ of freshly prepared kinase buffer containing $10 \mathrm{~mm} \mathrm{NaF}, 1 \mathrm{~mm} \mathrm{Na}_{3}(\mathrm{VO})_{4}$, and $10 \mathrm{mM} \mathrm{MnCl}_{2}$ for 15 minutes at $25^{\circ} \mathrm{C}$. Proteins were then separated by SDS-PAGE on a $10 \%$ gel, and dried gels were subjected to autoradiography.

\section{RNA Extraction and 5'RACE Reaction}

Total RNA was isolated from a frozen sample of the diagnostic lymph node biopsy using guanidineisothiocyanate extraction and cesium chloride gradient centrifugation. cDNA was obtained from $1.5 \mu \mathrm{g}$ of total RNA using SuperScript II reverse transcriptase (Life Technologies Inc, Paisley, United Kingdom) and $2.5 \mathrm{pmol} / \mathrm{L}$ of the ALK-specific primer 5'-ACCCCAATGGCAGCGAACAA - $3^{\prime}$. The RACE technique was used following the manufacturer's recommendations to obtain the $5^{\prime}$ sequence fused with the ALK gene. The ALK primers used for the amplification and to confirm the specificity of the PCR fragments obtained were previously described (Hernandez et al, 1999).

\section{DNA Sequencing}

The PCR products were extracted from $1 \%$ agarose gels and purified using the Concert Rapid Gel Extraction System (Life Technologies Inc.). These products were directly sequenced using the Dye Terminator Cycle Sequencing method (Applied Biosystems, Foster City, California) and the ABI PRISM 377 automated sequencer (Applied Biosystems).

\section{Expression Analysis of ALK Chimeric Transcripts}

cDNA was obtained from $1 \mu \mathrm{g}$ of total RNA by random priming and SuperScriptTM II Reverse transcriptase (Life Technologies Inc.) following the manufacturer's recommendations. Detection of hybrid MSN-ALK transcript was performed using Moe3U (5'CAGCTGGAGATGGCCCGACA-3') and GSP3 (5'CTTGGGTCGTTGGGCATTC-3') primers, yielding an amplified product of $298 \mathrm{bp}$. The PCR conditions were 35 cycles consisting of 45 seconds at $94^{\circ} \mathrm{C}, 45$ seconds at $60^{\circ} \mathrm{C}$, and 1 minute at $72^{\circ} \mathrm{C}$, with a final extension step of 10 minutes at $72^{\circ} \mathrm{C}$. NPM-ALK, TPM3-ALK, TFG-ALK, ATIC-ALK, and CLTCL-ALK expression was analyzed as previously described (Hernandez et al, 1999; Ma et al, 2000; Morris et al, 1994; Pulford et al, 1999b; Touriol et al, 2000). To analyze the possible expression of the reciprocal $A L K-M S N$ product, a heminested PCR strategy was used. The first PCR reaction was performed using the primers ALKD (5'-GGTGACCTCTGCCCTCGTGG-3') and Moe9D (5'-CAAGGACCGCAGTGAGGAGG-3'). The second round was performed using ALKD and Moe8D (5'-GCTGACCTACGGGCTGATGC-3') specific primers.

\section{DNA Extraction and Identification of the Genomic Breakpoint}

High-molecular-weight DNA was isolated from a frozen sample of the diagnostic lymph node by proteinase $\mathrm{K}$ treatment and phenol-chloroform extraction. Amplification of genomic breakpoint was performed using a semi-nested PCR strategy. The first round of PCR was performed using Moe3U and ALKGD (5'GCCCTGAGTACAAGCTGAGCA-3') primers, yielding a $465 \mathrm{bp}$ fragment. The PCR conditions were 35 cycles comprising a denaturing step at $94^{\circ} \mathrm{C}$ for 45 seconds, an annealing step of 45 seconds at $58^{\circ} \mathrm{C}$, and an elongation step of 1 minute and 30 seconds at $72^{\circ} \mathrm{C}$, followed by a final extension time of 7 minutes at $72^{\circ} \mathrm{C}$. The second round was performed using ALKGD and MoeGU (5'-GAGTGAGGCTGTGGAGTGGCA-3') primers, following the same conditions as in the first PCR reaction. This second PCR yielded an amplified product of $436 \mathrm{bp}$. The same semi-nested PCR strategy was used to analyze the derivative translocation. In this case, the first round of PCR was performed with ALKIU (5'-AGTGCTTCAAGGGCCAGGCT-3') and Moe9D primers to amplify an expected $179 \mathrm{bp}$ fragment. The second round of PCR was performed using ALKIU- and Moe8D-specific primers, obtaining an expected band of $155 \mathrm{bp}$. Both PCR reactions were performed following the same conditions as described above to amplify the genomic breakpoint. Finally, all of these PCR products were analyzed and sequenced as previously described.

\section{References}

Berryman M, Franck Z, and Bretscher A (1993). Ezrin is concentrated in the apical microvilli of a wide variety of 
epithelial cells whereas moesin is found primarily in endothelial cells. J Cell Sci 105:1025-1043.

Beylot-Barry M, Groppi A, Vergier B, Pulford K, and Merlio JP (1998). Characterization of $t(2 ; 5)$ reciprocal transcripts and genomic breakpoints in CD30+ cutaneous lymphoproliferations. Blood 91:4668-4676.

Bischof D, Pulford K, Mason DY, and Morris SW (1997). Role of the nucleophosmin (NPM) portion of the non-Hodgkin's lymphoma-associated NPM-anaplastic lymphoma kinase fusion protein in oncogenesis. Mol Cell Biol 17:2312-2325.

Bitter MA, Franklin WA, Larson RA, McKeithan TW, Rubin CM, Le Beau MM, Stephens JK, and Vardiman JW (1990). Morphology in Ki-1(CD30)-positive non-Hodgkin's lymphomas is correlated with clinical features and the presence of a unique chromosomal abnormality, t(2;5)(p23;q35). Am J Surg Pathol 14:305-316.

Bretscher A (1999). Regulation of cortical structure by the ezrin-radixin-moesin protein family. Curr Opin Cell Biol 11: $109-116$.

Chan PK, Chan FY, Morris SW, and Xie Z (1997). Isolation and characterization of the human nucleophosmin/b23 (NPM) gene: Identification of the YY1 binding site at the $5^{\prime}$ enhancer region. Nucleic Acids Res 25:1225-1232.

Chan WY, Liu QR, Borjigin J, Busch H, Rennert OM, Tease LA, and Chan PK (1989). Characterization of the cDNA encoding human nucleophosmin and studies of its role in normal and abnormal growth. Biochemistry 28:1033-1039.

Colleoni GW, Bridge JA, Garicochea B, Liu J, Filippa DA, and Ladanyi M (2000). ATIC-ALK: A novel variant ALK gene fusion in anaplastic large cell lymphoma resulting from the recurrent cryptic chromosomal inversion, inv(2)(p23q35). Am J Pathol 2000 Mar;156(3):781-9 156:781-789.

Downing JR, Shurtleff SA, Zielenska M, Curcio-Brint AM, Behm FG, Head DR, Sandlund JT, Weisenburger DD, Kossakowska AE, and Thorner P (1995) Molecular detection of the $(2 ; 5)$ translocation of non-Hodgkin's lymphoma by reverse transcriptase-polymerase chain reaction. Blood 85: 3416-3422.

Falini B, Bigerna B, Fizzotti M, Pulford K, Pileri SA, Delsol G, Carbone A, Paulli M, Magrini U, Menestrina F, Giardini R, Pilotti S, Mezzelani A, Ugolini B, Billi M, Pucciarini A, Pacini R, Pelicci PG, and Flenghi L (1998). ALK expression defines a distinct group of T/null lymphomas ("ALK lymphomas") with a wide morphological spectrum. Am J Pathol 153:875-886.

Fouassier L, Yun CC, Fitz JG, and Doctor RB (2000). Evidence for ERM binding phosphoprotein 50 (EBP50) selfassociation through PDZ-PDZ interactions. J Biol Chem 275:25039-25045.

Fujimoto J, Shiota M, Iwahara T, Seki N, Satoh H, Mori S, and Yamamoto T (1996). Characterization of the transforming activity of $\mathrm{p} 80$, a hyperphosphorylated protein in a Ki-1 lymphoma cell line with chromosomal translocation $t(2 ; 5)$. Proc Natl Acad Sci USA 93:4181-4186.

Hernandez L, Pinyol M, Hernandez S, Bea S, Pulford K, Rosenwald A, Lamant L, Falini B, Ott G, Mason DY, Delsol G, and Campo $E$ (1999). TRK-fused gene (TFG) is a new partner of ALK in anaplastic large cell lymphoma producing two structurally different TFG-ALK translocations. Blood 94: 3265-3268.

Iwahara T, Fujimoto J, Wen D, Cupples R, Bucay N, Arakawa T, Mori S, Ratzkin B, and Yamamoto T (1997). Molecular characterization of ALK, a receptor tyrosine kinase expressed specifically in the nervous system. Oncogene 14 : $439-449$.

Lamant L, Dastugue N, Pulford K, Delsol G, and Mariame B (1999). A new fusion gene TPM3-ALK in anaplastic large cell lymphoma created by a $(1 ; 2)(q 25 ; p 23)$ translocation. Blood 93:3088-3095.

Lamant L, Meggetto F, al Saati T, Brugieres L, de Paillerets BB, Dastugue N, Bernheim A, Rubie H, Terrier-Lacombe MJ, Robert A, Rigal F, Schlaifer D, Shiuta M, Mori S, and Delsol G (1996). High incidence of the $t(2 ; 5)(p 23 ; q 35)$ translocation in anaplastic large cell lymphoma and its lack of detection in Hodgkin's disease. Comparison of cytogenetic analysis, reverse transcriptase-polymerase chain reaction, and $p-80$ immunostaining. Blood 87:284-291.

Lamant L, Pulford K, Bischof D, Morris SW, Mason DY, Delsol G, and Mariame B (2000). Expression of the ALK tyrosine kinase gene in neuroblastoma. Am J Pathol 156: 1711-1721.

Ma Z, Cools J, Marynen P, Cui X, Siebert R, Gesk S, Schlegelberger B, Peeters B, de Wolf-Peeters C, Wlodarska I, and Morris SW (2000). Inv(2)(p23q35) in anaplastic largecell lymphoma induces constitutive anaplastic lymphoma kinase (ALK) tyrosine kinase activation by fusion to ATIC, an enzyme involved in purine nucleotide biosynthesis. Blood 95:2144-2149.

Mason DY, Bastard C, Rimokh R, Dastugue N, Huret JL, Kristoffersson U, Magaud JP, Nezelov C, Tilly H, and Vannier JP (1990) CD30-positive large cell lymphomas ("Ki-1 lymphoma") are associated with a chromosomal translocation involving 5q35. Br J Haematol 74:161-168.

Mason DY, Micklem K, and Jones M (2000). Double immunofluorescence labelling of routinely processed paraffin sections. J Pathol 191:452-461.

Mason DY, Pulford KA, Bischof D, Kuefer MU, Butler LH, Lamant L, Delsol G, and Morris SW (1998). Nucleolar localization of the nucleophosmin-anaplastic lymphoma kinase is not required for malignant transformation. Cancer Res 58: 1057-1062.

Masumoto J, Sagara J, Hayama M, Hidaka E, Katsuyama T, and Taniguchi S (1998). Differential expression of moesin in cells of hematopoietic lineage and lymphatic systems. Histochem Cell Biol 110:33-41.

Mitev L, Christova S, Hadjiev E, Guenova M, Oucheva R, Valkov I, and Manolova Y (1998). A new variant chromosomal translocation $\mathrm{t}(2 ; 2)(\mathrm{p} 23 ; \mathrm{q} 23)$ in $\mathrm{CD} 30+/ \mathrm{Ki}-1+$ anaplastic large cell lymphoma. Leuk Lymphoma 28:613-616.

Morris SW, Kirstein MN, Valentine MB, Dittmer KG, Shapiro DN, Saltman DL, and Look AT (1994). Fusion of a kinase gene, ALK, to a nucleolar protein gene, NPM, in nonHodgkin's lymphoma. Science 263:1281-1284.

Morris SW, Naeve C, Mathew P, James PL, Kirstein MN, Cui $X$, and Witte DP (1997). ALK, the chromosome 2 gene locus altered by the $\mathrm{t}(2 ; 5)$ in non-Hodgkin's lymphoma, encodes a novel neural receptor tyrosine kinase that is highly related to leukocyte tyrosine kinase. Oncogene 14:2175-2188.

Park JP, Curran MJ, Levy NB, Davis TH, Elliott JH, and Mohandas TK (1997). Diffuse large cell, B-cell type lymphoma with a novel translocation (2;22)(p23;q11.2). Cancer Genet Cytogenet 96:118-122. 
Pittaluga S, Wiodarska I, Pulford K, Campo E, Morris SW, Van den Berghe H, and de Wolf-Peeters C (1997). The monoclonal antibody ALK1 identifies a distinct morphological subtype of anaplastic large cell lymphoma associated with 2p23/ALK rearrangements. Am J Pathol 151:343-351.

Pulford K, Delsol G, Roncador G, Biddolph S, Jones M, and Mason DY (1999a). Immunohistochemical screening for oncogenic tyrosine kinase activation. J Pathol 187:588-593.

Pulford K, Falini B, Cordell J, Rosenwald A, Ott G, MullerHermelink HK, MacLennan KA, Lamant L, Carbone A, Campo E, and Mason DY (1999b). Biochemical detection of novel anaplastic lymphoma kinase proteins in tissue sections of anaplastic large cell lymphoma. Am J Pathol 154:1657-1663.

Pulford K, Lamant L, Morris SW, Butler LH, Wood KM, Stroud D, Delsol G, and Mason DY (1997). Detection of anaplastic lymphoma kinase (ALK) and nucleolar protein nucleophosmin (NPM)-ALK proteins in normal and neoplastic cells with the monoclonal antibody ALK1. Blood 89:1394-1404.

Reczek D, Berryman M, and Bretscher A (1997). Identification of EBP50: A PDZ-containing phosphoprotein that associates with members of the ezrin-radixin-moesin family. J Cell Biol 139:169-179.

Reczek D and Bretscher A (1998). The carboxyl-terminal region of EBP50 binds to a site in the amino-terminal domain of ezrin that is masked in the dormant molecule. $\mathrm{J}$ Biol Chem 273:18452-18458.

Rosenwald A, Ott G, Pulford K, Katzenberger T, Kuhl J, Kalla J, Ott MM, Mason DY, and Muller-Hermelink HK (1999). $\mathrm{t}(1 ; 2)(\mathrm{q} 21 ; \mathrm{p} 23)$ and $\mathrm{t}(2 ; 3)(\mathrm{p} 23 ; \mathrm{q} 21)$ : Two novel variant translocations of the $\mathrm{t}(2 ; 5)(\mathrm{p} 23 ; q 35)$ in anaplastic large cell lymphoma. Blood 94:362-364.

Sainati L, Montaldi A, Stella M, Putti MC, Zanesco L, and Basso G (1990). A novel variant translocation $t(2 ; 13)(p 23 ; q 34)$ in $\mathrm{Ki}-1$ large cell anaplastic lymphoma. $\mathrm{Br} \mathrm{J}$ Haematol 75 : 621-622.
Sarris AH, Luthra R, Cabanillas F, Morris SW, and Pugh WC (1998). Genomic DNA amplification and the detection of $\mathrm{t}(2$; 5)(p23; q35) in lymphoid neoplasms. Leuk Lymphoma 29: 507-514.

Touriol C, Greenland C, Lamant L, Pulford K, Bernard F, Rousset T, Mason DY, and Delsol G (2000). Further demonstration of the diversity of chromosomal changes involving 2p23 in ALK-positive lymphoma: 2 cases expressing ALK kinase fused to CLTCL (clathrin chain polypeptide-like). Blood 95:3204-3207.

Trinei M, Lanfrancone L, Campo E, Pulford K, Mason DY, Pelicci PG, and Falini B (2000). A new variant anaplastic lymphoma kinase (ALK)-fusion protein (ATIC-ALK) in a case of ALK-positive anaplastic large cell lymphoma. Cancer Res 60:793-798.

Tsukita S and Yonemura S (1997a). ERM proteins: Head-totail regulation of actin-plasma membrane interaction. Trends Biochem Sci 22:53-58.

Tsukita S and Yonemura S (1997b). ERM (ezrin/radixin/ moesin) family: From cytoskeleton to signal transduction. Curr Opin Cell Biol 9:70-75.

Tsukita S and Yonemura S (1999). Cortical actin organization: Lessons from ERM (ezrin/radixin/moesin) proteins. J Biol Chem 274:34507-34510.

Wlodarska I, de Wolf-Peeters C, Falini B, Verhoef G, Morris SW, Hagemeijer A, and Van de Berghe H (1998). The cryptic inv(2)(p23q35) defines a new molecular genetic subtype of ALK-positive anaplastic large-cell lymphoma. Blood 92: 2688-2695.

Zucman-Rossi J, Legoix P, Victor JM, Lopez B, and Thomas G (1998). Chromosome translocation based on illegitimate recombination in human tumors. Proc Natl Acad Sci USA 95:11786-11791. 